\title{
Decreased Physical Activity Associated with Executive Dysfunction Correlates with Cognitive Impairment among Older Adults in the Community: A Retrospective Analysis from the Kurihara Project
}

\author{
Yoritoshi Kobayashi Yumi Takahashi Takashi Seki Tomohiro Kaneta \\ Kenichi Amarume Mari Kasai Kenichi Meguro members of the Kurihara \\ Project
}

Division of Geriatric Behavioral Neurology, CYRIC, Tohoku University Sendai, Japan

\section{Key Words}

Mild cognitive impairment - Dementia - Clinical Dementia Rating · Physical activity ·

Executive function - Retrospective study

\section{Abstract}

Background/Aims: No previous studies have explored the relationship between physical activity (PA) and executive dysfunction. Methods: We retrospectively evaluated the PA for 590 older participants in the Kurihara Project; 221 participants had a Clinical Dementia Rating (CDR) of 0 (healthy), 295 CDR 0.5 (very mild dementia), and 74 CDR 1+ (dementia). Results: In the complicated task, whether the motor intensity was high (e.g. farming) or low (e.g. shopping), PA exhibited an inverse relationship with the CDR level. By contrast, for simple tasks with high intensity (e.g. walking), no CDR group differences were noted. For PA with low intensity (e.g. cleaning), the CDR 1+ group exhibited decreased levels. Conclusion: PA was related to the burden of executive function in patients with mild cognitive impairment; however, in patients with dementia, PA was related to both the burden of executive function and motor intensity. 
Kobayashi et al.: Physical Activity and Executive Dysfunction

\section{Introduction}

Dementia is characterized by memory loss that occurs in combination with impairment of other cognitive functions (e.g. behavior, personality changes, social functioning and/or the inability to perform activities of daily living) [1]. Physical activity (PA) has been consistently associated with decreased risk of cognitive decline and dementia, and its positive effects are evident for both Alzheimer's disease (AD) and vascular dementia [2, 3]. PA refers to any body movement that is produced as a result of contraction of skeletal muscles and that increases energy expenditure [4]. Exercise refers to planned, structured, and repetitive movement to improve or maintain one or more components of physical fitness [4]. Therefore, PA consists of exercise and all of the body movements involved in daily living, including housework and labor.

In the relationship between PA and dementia, the highest PA category is associated inversely with the risk of dementia and AD in the Cochrane Database of Systematic Reviews and in prospective epidemiological studies on the Web of Science databases [5]. PA has been reported to be a protective factor against incident dementia in a population-based cohort [6]. However, some systematic reviews have shown no evidence of benefit from exercise on cognition and neuropsychiatric symptoms [7], and a low statistical power of the effects of exercise on global cognition [8].

For the relationship between PA and mild cognitive impairment (MCI) including very mild dementia, some prospective cohort studies have revealed the following: (1) greater levels of PA were associated with a lower risk of incident MCI among the otherwise cognitively normal elderly [9]; (2) high levels of participation in PA were associated with reduced risk of dementia among the elderly with MCI [10], and (3) women who were engaged in aerobic exercise exhibited cognitive benefits, with improved performance on tasks of executive function [11]. However, while exercise in the elderly with MCI improved their cardiovascular fitness, no improvements in cognitive function were observed. It would appear that exercise may be beneficial prior to the onset of MCI but is less helpful after its onset [12]. Furthermore, low levels of light-intensity PA were not associated with any reduction in brain atrophy [13]. Meanwhile, the effects of light PA on memory among the elderly with MCI are not mediated by changes in the hippocampal volume [14].

With respect to the relationship between PA and executive function, some prospective cohort studies for elderly with AD have revealed that higher habitual PA levels were associated with reduced changes in executive function (map search task, digit symbol substitution task, controlled oral word association task, and verbal fluency task) [15]. Habitual PA status was associated with executive performance [16]. Furthermore, social participation was predictive of two domains of cognitive and executive function. The relative magnitude of this effect was comparable to PA level in a large cohort study [17]. However, those results also evaluated various levels/intensities of PA.

Considering these studies, there is promising evidence that PA can significantly improve cognitive function in people with dementia and their ability to perform daily activities, but there remains a lot of variation between trial results that were not explained, and the mechanisms implicated in this effect remain unclear [6]. There is little to no evidence supporting a relationship between PA (frequency, intensity, duration, type of activity, etc.) and cognitive decline (cognitively normal, MCI, and dementia) [11]. In particular, to date, no study has addressed the approach from the data of random sampling among the community-dwelling elderly.

The aim of this study was to clarify the relationship between executive dysfunction of PA in daily living and dementia. Using the database of the Kurihara Project, a community-based prevention program of stroke and dementia in Kurihara, the PA of healthy aging adults and adults with dementia was analyzed retrospectively. 


\section{Materials and Methods}

\section{Subjects}

The Kurihara Project (2008-2010) was performed to focus on the old-old population ( $\geq 75$ years old) for the prevention of stroke, dementia and bed confinement in Kurihara City, an agricultural town of 76,708 (Nov. 2015) in Miyagi Prefecture, northern Japan [18]. The study included 590 of the 1,252 subjects aged $\geq 75$ years who underwent health examinations and provided informed consent for data analysis.

The study protocol was approved by the Institutional Review Board of the Tohoku University Graduate School of Medicine. The study conformed to the STROBE guidelines for cohort studies.

\section{Clinical Dementia Rating Assessment}

The clinical team, comprised of medical doctors and public health nurses who determined the Clinical Dementia Rating (CDR) for each participant, was blinded to the cognitive test results. Prior to the interviews with the doctors, public health nurses visited the participants' homes to evaluate their daily activities. Observations by family regarding the participants' lives were described using a semistructured questionnaire. Participants who lived alone were excluded from this investigation. The participants were then interviewed by doctors to assess episodic memory, orientation, etc. Finally, with reference to the information provided by the family, the participants' CDR stages were determined at a joint meeting. A reliable Japanese version of the CDR worksheet [19] was established, and dementia was diagnosed based on the DSM-IV criteria. One author (K.M.) was certified as a CDR rater at the Washington University School of Medicine Alzheimer's Disease Research Center Memory and Aging Project.

\section{Assessment of Cognitive Impairment and Depression}

Cognitive impairment was evaluated by the CDR [20] from the database of the Basic Information of Users (BIU) [21]. We categorized 590 subjects into 3 groups according to their CDR: the CDR 0 group $(n=221)$, which means they were healthy elderly; the CDR 0.5 group $(n=295)$, which means they had very mild dementia, and the CDR $1+$ group $(n=74)$, which means they had dementia [22]. Also, we examined the impact of depression on cognitive decline. Depression was assessed by the short version of the Geriatric Depression Scale (GDS-15) cutoff score of 5/6 (low: $<5$, high: $\geq 6$ ) indicating more severe depressive symptoms [23].

\section{Assessment of Daily PA}

PA in daily living was evaluated based on 23 items (table 1) in the BIU database. The public health nurses visited the subjects' homes to evaluate their daily activities. Observations by family members regarding the subjects' lives were recorded using a semistructured questionnaire. The 23 items were classified PA codes and metabolic equivalent (MET) values of the American College of Sports Medicine (ACSM) [24]. The classification of PA was evaluated using a double-blind trial, and the reliability testing was evaluated using the intraclass correlation coefficient (ICC) [25]. ICC assessment was 0.913 ( $p<0.0001$ : almost perfect) when 33 randomly selected subjects out of the 590 subjects were tested.

PA was classified into 4 groups according to the intensity level of PA and executive function. PA intensity was the evaluated METs according to the criteria of the ACSM [24]. The amount of time spent on PA (h/day) was estimated using the data from the Multiple Indicator Cluster Surveys (MIC Survey) on the 2011 Survey on Time Use and Leisure Activities of Japan (see Appendix) [26], because it was not assessed in the Kurihara Project. The amount (intensi- 
Table 1. METs and executive function level on PA items [24]

\begin{tabular}{|c|c|c|}
\hline Item of specific activity & METs & Executive function \\
\hline \multicolumn{3}{|l|}{ [Sedentary behavior (1.0-1.5 METs)] } \\
\hline Participating in community activities (voluntary) & 1.5 & complicated task \\
\hline Participating in a senior citizen's club & 1.5 & \\
\hline Miscellaneous activities (e.g. reading, arts) & 1.5 & \\
\hline Participating in community activities (involuntary) & 1.5 & simple task \\
\hline Bathing (independent self-care) & 1.5 & \\
\hline Child care or elderly care & 1.5 & \\
\hline \multicolumn{3}{|l|}{ [Light intensity (1.6-2.9 METs)] } \\
\hline Shopping (with/without a cart, standing/walking) & 2.3 & complicated task \\
\hline Long-distance travel (by car or public transportation) & 2.0 & \\
\hline Interaction with one's neighbors & 2.0 & \\
\hline Cooking or food preparation & 2.0 & \\
\hline Recreational activities (e.g. traveling, crafts, music) & 2.0 & \\
\hline Walking (very slow paced walking inside/around the house) & 2.0 & simple task \\
\hline Preparation of farming tools (e.g. sharpening tools) & 2.0 & \\
\hline Cleaning or laundry (general household cleaning and laundry) & 2.0 & \\
\hline \multicolumn{3}{|l|}{ [Moderate intensity (3-5.9 METs) and vigorous intensity ( $\geq 6$ METs)] } \\
\hline Farming (e.g. rice, planting, care of animals) & 4.8 & complicated task \\
\hline Gardening (e.g. planting trees, crops, garden) & 4.3 & \\
\hline Working or participating in volunteer activities (walk/stand combination) & 3.0 & \\
\hline Gardening (e.g. weeding, removing snow or leaves) & 3.8 & simple task \\
\hline Walking (e.g. for pleasure, dog, to work, moderate paced walking) & 3.5 & \\
\hline Light intensity activities (e.g. calisthenics, petanque) & 3.5 & \\
\hline Moderate intensity activities (e.g. ballroom dance, softball, golf) & 4.0 & \\
\hline Vigorous intensity activities (e.g. jogging, swimming, tennis) & 8.3 & \\
\hline Resistance training (e.g. muscular endurance, circuit/curves) & 5.0 & \\
\hline
\end{tabular}

Levels of executive function were categorized into dichotomous variables with a similar number of individuals according to whether the PA is a simple task or a complicated task.

ty $\times$ duration) of PA was calculated by METs $\times$ h/day. For example, the PA of 'shopping' is calculated using table 1 and the appendix as follows:

$\mathrm{PA}=[(68 \mathrm{~min} / 60 \mathrm{~min}) \times 3$ days $/$ week $)] \times(2.3 \mathrm{METs})=1.1 \mathrm{METs} \times \mathrm{h} /$ day

PA was then categorized into 2 groups (high: $\geq 3$ METs, low: $<3$ METs) by intensity activity according to the criteria of the ACSM [27].

\section{Assessment of Executive Function}

Several long-term trials have shown that PA is associated with executive function [15, 28]. The PAs that showed effects towards executive function are as follows: aerobic walking [29], dual task-based exercise training [30], two sessions of exercise training [31], stepping activity [32], crossing a street at a pedestrian traffic light [33], and social participation [17]. Conversely, the PAs that did not show any positive effects on executive function include stretching and balance exercises [34], slow jogging [35], resistance exercise [36], moderateintensity walking exercise [37], flexibility training [38], and single-task training [34]. These results suggested that dual task-based PA (which is complex PA) affected executive function, but single task-based PA (which is simple PA) whether PA is low or high exhibited no effect. We categorized the 23 items of PA in BIU data into 2 groups: complex tasks (e.g. shopping, 
Table 2. Baseline demographics and clinical characteristics

\begin{tabular}{lccc}
\hline & CDR 0 & CDR 0.5 & CDR $1+$ \\
\hline Participants, $\mathrm{n}$ & 221 & 295 & 74 \\
Men, $\mathrm{n}^{\dagger}$ & $92(41.6 \%)$ & $108(36.6 \%)$ & $25(33.8 \%)$ \\
Age, years & $79.0 \pm 3.6^{\mathrm{b}}$ & $80.4 \pm 4.3^{\mathrm{a}}$ & $82.3 \pm 4.4^{\mathrm{a}, \mathrm{b}}$ \\
Educational level & $9.3 \pm 2.1^{\mathrm{b}}$ & $8.5 \pm 1.7^{\mathrm{a}}$ & $7.8 \pm 1.5^{\mathrm{a}, \mathrm{b}}$ \\
MMSE & $25.4 \pm 2.6^{\mathrm{b}}$ & $22.8 \pm 3.4^{\mathrm{a}}$ & $16.2 \pm 5.4^{\mathrm{a}, \mathrm{b}}$ \\
GDS & $3.9 \pm 2.6^{\mathrm{b}}$ & $4.8 \pm 3.1^{\mathrm{a}}$ & $6.1 \pm 3.2^{\mathrm{a}, \mathrm{b}}$ \\
\hline
\end{tabular}

Statistical analyses: ANOVA (post hoc test; Bonferroni test). ${ }^{\dagger} \chi^{2}$ test, $\mathrm{p}<0.05$. ${ }^{\text {a }}$ Significant difference with CDR 0 ( $p<0.05)$. ${ }^{b}$ Significant difference with CDR $0.5(p<0.05)$. Values for age, educational level, MMSE and GDS are expressed as mean \pm SD.

cooking, and farming) or simple tasks (e.g. walking, jogging, and removing snow) (table 1). In the cases exhibiting both tasks, the item of PA was categorized into the dichotomous groups of simple versus complicated tasks.

\section{Statistical Analysis}

In order to examine the interaction between the amount of daily PA and executive function, stratification analysis of the level of executive function was conducted. The analysis was performed to examine the contribution of CDR and PA intensity to PA amount. All statistical analyses were performed using SPSS version 20.0 (SPSS Japan Inc., Tokyo, Japan). Since the distribution of all continuous variables was not normal, the common logarithm was applied to normalize the data prior to analysis. Logarithmic transformation of the continuous covariates resulted in near-normalized distribution of the variables. The participants' characteristics at baseline were compared using analysis of variance. Dichotomous variables were expressed as percentages and continuous variables as the median (interquartile range). The analyses were performed after adjustment for age and sex. All statistical analyses were 2 -tailed, and $p$ values $<0.05$ were considered significant.

\section{Results}

\section{Prevalence of Dementia}

Of the 590 subjects who agreed to take part in the study and underwent clinical examination, $221(37.5 \%)$ were healthy, $295(50.0 \%)$ had very mild dementia, and $74(12.5 \%)$ had dementia. As we reported the prevalence of dementia in Japan, the ratio of prevalence exhibits both reliability and validity [39]. Table 2 presents the demographic data of the three CDR groups. There were no significant differences in sex among the three groups. The CDR 1+ group was the oldest with the lowest education level and Mini-Mental State Examination (MMSE) score, and the highest GDS score. The CDR 0.5 group was older with a lower education level and MMSE score, and a higher GDS score compared with the CDR 0 group.

\section{The Total Amount of PA and CDR Level}

Table 3 presents the results of analysis of covariance (ANCOVA) of the relationship between the total amount of PA (PA amount) and the CDR level. The CDR 0.5 group exhibited a lower PA amount than the CDR 0 group $(\mathrm{p}<0.001)$. The CDR $1+$ group exhibited a lower PA 
Table 3. Total PA (95\% CI) by CDR categories

\begin{tabular}{|c|c|c|c|c|}
\hline & \multicolumn{3}{|l|}{ Total PA by CDR } & \multirow{2}{*}{$\begin{array}{l}\mathrm{p} \text { for } \\
\text { trend }\end{array}$} \\
\hline & CDR 0 & CDR 0.5 & CDR 1+ & \\
\hline Total PA & $9.74(9.40-10.08)$ & $8.70(8.41-9.00)^{\mathrm{a}}$ & $4.90(4.31-5.50)^{\mathrm{a}, \mathrm{b}}$ & 0.000 \\
\hline \multicolumn{5}{|l|}{ Total PA by intensity } \\
\hline Light PA ( $<3$ METs) & $6.82(6.62-7.03)$ & $6.39(6.22-6.57)^{\mathrm{a}}$ & $3.60(3.25-3.96)^{a, b}$ & 0.000 \\
\hline High PA ( $\geq 3$ METs) & $2.92(2.66-3.18)$ & $2.31(2.09-2.53)^{\mathrm{a}}$ & $1.30(0.85-1.75)^{a, b}$ & 0.000 \\
\hline
\end{tabular}

PA was calculated by METs $\times$ h/day. Statistical analyses: ANOVA (Bonferroni test) adjusted for sex and age. ${ }^{\text {a }}$ Significant difference with CDR 0 ( $\left.\mathrm{p}<0.05\right)$. ${ }^{\mathrm{b}}$ Significant difference with CDR $0.5(\mathrm{p}<0.05)$.

amount than both the CDR 0 and 0.5 groups $(\mathrm{p}<0.001)$. Next, the PA amount was classified into two groups based on PA intensity (light PA: $<3$ METs, high PA: $\geq 3$ METs) and ANCOVA was conducted. The PA amount of the light-intensity group decreased progressively from the CDR 0 group to the CDR $1+$ group ( $<0.001$ ). Similarly, the PA amount of the high-intensity group also decreased progressively according to the CDR group $(\mathrm{p}<0.001)$.

\section{PA Amount and CDR Level Stratified by the Level of Executive Function}

In order to further examine the interaction between PA amount and executive function, stratification analysis of the level of executive function was performed. The analysis was performed by two groups classified as GDS score because there is interaction between depression and PA intensity. Table 4 presents the ANCOVA for the relationships between the PA amount and the CDR categories after performing the stratification analysis of the executive function level and GDS.

In the complicated task of executive function, the light-intensity (e.g. shopping) and highintensity (e.g. farming) PA groups showed that the PA amount of the CDR 0.5 group was lower than the PA amount of the CDR 0 group $(\mathrm{p}<0.0001)$ and that the PA amount of the CDR $1+$ group was lower than that of the CDR 0.5 group ( $<0.001$ ) (p for trend $<0.0001$ ). In the simple task, the high-intensity PA group (e.g. walking) showed similar PA amounts for all 3 CDR groups. In the light-intensity PA group (e.g. cleaning), there was no statistical difference in the PA amount between the CDR 0 and CDR 0.5 groups. However, the PA amount of the CDR $1+$ group was lower than those of the CDR 0 and 0.5 groups (each $p<0.0001$ ). Those results were significant relationships independent of GDS and education level.

\section{Discussion}

This retrospective study investigated the relationships between PA and executive function and dementia. In particular, the diagnosis of dementia was determined using evidence-based medicine with the CDR and was classified into 3 categories (healthy, very mild dementia, and dementia). Our results suggest that cognitive decline is related to the burden of executive function of PA in daily living.

\section{Prevalence of Dementia}

The prevalence of dementia and very mild dementia among all of the participants was 12.5 and $50.0 \%$, respectively. The prevalence of dementia in Japan has been reported to vary from 3.8 to $11.0 \%$ among those aged 65 years and older [39]. However, though there have 
Kobayashi et al.: Physical Activity and Executive Dysfunction

Table 4. Total PA (95\% CI) stratified by the level of executive function with GDS and intensity for CDR categories

\begin{tabular}{|c|c|c|c|c|c|c|}
\hline & \multicolumn{3}{|l|}{ Total PA by CDR } & \multirow[t]{2}{*}{$\begin{array}{l}\mathrm{p} \text { for } \\
\text { trend }\end{array}$} & \multicolumn{2}{|c|}{$\begin{array}{l}\text { Effect of } \\
\text { education }\end{array}$} \\
\hline & CDR 0 & CDR 0.5 & CDR $1+$ & & $\mathrm{F}$ & $\mathrm{p}$ \\
\hline \multicolumn{7}{|c|}{ Total PA in simple executive function } \\
\hline Light PA with low GDS & $2.19(2.10-2.27)$ & $2.21(2.13-2.29)$ & $1.50(1.30-1.69)^{\mathrm{a}, \mathrm{b}}$ & 0.000 & 1.25 & 0.264 \\
\hline Light PA with high GDS & $2.36(2.18-2.53)$ & $2.26(2.14-2.39)$ & $1.54(1.33-1.75)^{\mathrm{a}, \mathrm{b}}$ & 0.000 & 3.04 & 0.083 \\
\hline High PA with low GDS & $0.90(0.69-1.11)$ & $1.01(0.82-1.21)$ & $0.83(0.34-1.32)$ & 0.806 & 0.29 & 0.589 \\
\hline High PA with high GDS & $0.67(0.35-0.99)$ & $0.73(0.50-0.96)$ & $0.29(0.10-0.68)$ & 0.151 & 0.00 & 0.953 \\
\hline \multicolumn{7}{|c|}{ Total PA in complicated executive function } \\
\hline Light PA with low GDS & $4.68(4.50-4.87)$ & $4.30(4.13-4.46)^{\mathrm{a}}$ & $2.35(1.92-2.78)^{a, b}$ & 0.000 & 0.17 & 0.678 \\
\hline Light PA with high GDS & $4.44(4.08-4.81)$ & $3.88(3.62-4.15)^{\mathrm{a}}$ & $2.00(1.56-2.45)^{\mathrm{a}, \mathrm{b}}$ & 0.000 & 0.42 & 0.518 \\
\hline High PA with low GDS & $2.07(1.83-2.31)$ & $1.55(1.33-1.76)^{\mathrm{a}}$ & $0.74(0.19-1.30)^{\mathrm{a}, \mathrm{b}}$ & 0.000 & 2.08 & 0.151 \\
\hline High PA with high GDS & $2.19(1.78-2.61)$ & $1.13(0.83-1.42)^{\mathrm{a}}$ & $0.65(0.14-1.15)^{\mathrm{a}}$ & 0.000 & 0.04 & 0.838 \\
\hline
\end{tabular}

Low GDS: $<5$, high GDS: $\geq 6$; PA was calculated by METs $\times$ h/day. Statistical analysis: ANOVA (Bonferroni test) adjusted for sex, age, education, and GDS. ${ }^{a}$ Significant difference with CDR $0(\mathrm{p}<0.05)$. ${ }^{\mathrm{b}}$ Significant difference with CDR $0.5(\mathrm{p}<0.05)$.

been no previous reports of the prevalence among the old-old population, aged 75 years and older, we reported the prevalence with reliability and validity [39].

\section{PA Amount and CDR Level}

We initially examined the relationships between the PA amount and CDR level, and showed that the PA amount decreased in a step-wise manner in the CDR 0, 0.5, and 1+ groups. The inverse correlation between PA and CDR level supported these findings even when the PA amount was classified by PA intensity.

The majority of published evidence from the observational and controlled studies conducted to date clearly underscores the positive association between PA and cognitive function [40]. One prospective study investigated the long-term influence of PA on the risk of dementia among the elderly Japanese population [41], and showed that the active group showed significantly lower crude incidence of $\mathrm{AD}$ compared with the inactive group. Furthermore, several studies have shown that regular PA could represent an important and potent protective factor for cognitive decline and dementia in elderly persons [7, 42]. The current results confirm the previous findings of a positive effect of PA on cognitive function among elderly adults.

\section{PA Amount and Executive Function among the CDR Groups}

We performed a stratified analysis of the relationships between CDR level and PA amount according to the burden of executive function. The results of the stratification analysis of CDR level and PA amount suggest the following: for the complicated task, whether PA intensity was high (e.g. farming) or low (e.g. shopping), PA amount exhibited an inverse relationship with the CDR level. By contrast, simple tasks exhibited different results. Specifically, for the high-intensity PA group (e.g. walking), there were no differences based on the CDR grouping. However, for the low-intensity PA group (e.g. cleaning), the CDR 1+ group exhibited a lower PA amount compared with the CDR 0 and 0.5 groups. The association between PA and CDR was an independent relationship; thus, it is not influenced by educational level, GDS, and age.

Our study indicated a significant relationship between PA and executive function. Higherlevel executive function was reported to be necessary for the regulation of PA in a cohort study [32]. Improvements in executive function correlated with increases in gait speed and PA in a 
prospective cohort study of community-dwelling older adults with falls [43]. In an observational study, the prevalence and severity of executive dysfunction were demonstrated in AD patients [44]. Furthermore, several prospective studies have reported that social participation is positively associated with executive function $[17,45]$. The results also revealed that the PA amount in the daily living of the CDR 0 group is higher than in the CDR 1+ group in both the simple and complicated task groups of executive function. In a 1-year cohort study of executive function changes in elderly with AD, higher habitual PA levels were associated with reduced change in executive function [15], and in longitudinal multilevel models, low levels of PA led to subsequent declines in executive function among older adults [46]. However, our study indicated that whether the PA level was high or low, the PA with the complicated task exhibited an inverse relationship with CDR level. Considering these findings, our results indicated that long-term PA with the complicated task in daily living might decrease according to the dementia severity.

Interestingly, we reported various findings of PA amount among the CDR categories depending on PA intensity and the levels of executive function. The higher PA levels in participants with/without cognitive impairment were associated with significantly higher whole-brain and parietal lobe volume, and reduced ventricular dilation. Furthermore, AD and very mild dementia correlated significantly with lower brain volume across the whole brain, with pervasive associations revealing frontal lobe atrophy and ventricular dilation [47]. PA was associated independently with greater whole brain and regional brain volumes and reduced ventricular dilation. Our findings suggest that the effect of PA on the elderly with cognitive impairment may be related not only to PA intensity, but also the type/levels of executive function.

\section{Limitations and Conclusion}

The present study has several limitations. Firstly, this was a retrospective analysis that used the database of the Kurihara Project; unfortunately, the database did not investigate the actual time of PA. We estimated the duration and the frequency of PA using data from the Statistics Bureau of Japan. This may be a major limitation because all statistical work is based on estimated data. It is impossible to draw the direction of the relationship. The association may be just a consequence of progression of cognitive decline (more difficult activities were drawn earlier). In addition, PA was based on a recording by recall method, in which no information was obtained regarding the actual activities for each PA session.

Moreover, because this was an observational study, we could not conclude whether PA with the complicated task reduced the risk for dementia and functional decline. Therefore, an intervention trial should be undertaken to confirm the existence of a relationship between PA and the complicated task and dementia and functional decline.

In conclusion, our study found that PA was related to the burden of executive function for MCI; however, PA for dementia was related to both the burden of executive function and level of motor intensity. Since previous reports on 'exercise' interventions for dementia prevention have not considered the burden of executive function, we should be cautious in our interpretation of such results. 
Kobayashi et al.: Physical Activity and Executive Dysfunction

\section{Appendix}

The Amount of Time Spent on PA Using the Data from MIC Survey in Japan, 2011

\begin{tabular}{|c|c|c|c|c|}
\hline \multirow[t]{2}{*}{ Item of specific activity } & \multicolumn{2}{|c|}{$\begin{array}{l}\text { Time spent per } \\
\text { day, min }\end{array}$} & \multicolumn{2}{|c|}{$\begin{array}{l}\text { Frequency per } \\
\text { week, days }\end{array}$} \\
\hline & men & women & men & women \\
\hline Participating in community activities (voluntary) & 93 & 97 & 1.3 & 1.1 \\
\hline Participating in a senior citizen's club & 96 & 97 & 1.3 & 1.3 \\
\hline Miscellaneous activities (e.g. reading, arts) & 93 & 81 & 1.3 & 1.2 \\
\hline Participating in community activities (involuntary) & 93 & 97 & 1.3 & 1.1 \\
\hline Bathing (independent self-care) & 39 & 42 & 7.0 & 7.0 \\
\hline Child care or elderly care & 15 & 64 & 0.8 & 0.7 \\
\hline Shopping (with/without a cart, standing/walking) & 68 & 64 & 3.0 & 3.0 \\
\hline Long distance travel (by car or public transportation) & 73 & 60 & 5.0 & 5.0 \\
\hline Interaction with one's neighbors & 73 & 60 & 5.0 & 5.0 \\
\hline Cooking or food preparation & 88 & 131 & 2.7 & 2.8 \\
\hline Recreational activities (e.g. traveling, crafts, music) & 73 & 60 & 0.9 & 1.2 \\
\hline Walking (very slow paced walking inside/around the house) & 38 & 25 & 3.2 & 2.9 \\
\hline Preparation of farming tools (e.g. sharpening tools) & 64 & 75 & 1.9 & 1.9 \\
\hline Cleaning or laundry (general household cleaning and laundry) & 64 & 75 & 2.7 & 2.8 \\
\hline Farming (e.g. rice, planting, care of animals) & 142 & 123 & 1.9 & 1.9 \\
\hline Gardening (e.g. planting trees, crops, garden) & 121 & 47 & 1.9 & 1.9 \\
\hline Working or participating in volunteer activities (walk/stand combination) & 169 & 147 & 0.8 & 0.6 \\
\hline Gardening (e.g. weeding, removing snow or leaves) & 142 & 123 & 1.9 & 1.9 \\
\hline Walking (e.g. for pleasure, dog, to work, moderate paced walking) & 81 & 66 & 3.2 & 2.9 \\
\hline Light intensity activities (e.g. calisthenics, petanque) & 81 & 66 & 1.6 & 1.7 \\
\hline Moderate intensity activities (e.g. ballroom dance, softball, golf) & 81 & 66 & 1.5 & 1.5 \\
\hline Vigorous intensity activities (e.g. jogging, swimming, tennis) & 81 & 66 & 2.3 & 2.1 \\
\hline Resistance training (e.g. muscular endurance, circuit/curves) & 81 & 66 & 2.5 & 2.4 \\
\hline
\end{tabular}

MIC = The Multiple Indicator Cluster Surveys (MIC survey) on The 2011 Survey on Time Use and Leisure Activities of Japan. Survey subjects: age, $\geq 75$ years; area: the countryside of the Miyagi Prefecture.

\section{Acknowledgements}

The authors are grateful to the staff at Kurihara City government, especially to the public health nurses, and the staff at the Division of Geriatric Behavioral Neurology, CYRIC, Tohoku University, especially to Yuka Kato, Junko Takada, Mika Kumai, Masahiro Nakatsuka, Keiichi Kumai, Fumiko Nakashima, and Kei Nakamura.

\section{Disclosure Statement}

None of the authors have any conflicts of interest to declare. 
Kobayashi et al.: Physical Activity and Executive Dysfunction

\section{References}

1 American Psychiatric Association: Diagnostic and Statistical Manual of Mental Disorders, ed 4, text revision. Washington, American Psychiatric Association, 2000.

2 Rockwood K, Middleton L: Physical activity and the maintenance of cognitive function. Alzheimers Dement 2007;3:S38-S44.

3 Beeri MS, Middleton L: Being physically active may protect the brain from Alzheimer disease. Neurology 2012; 78:1290-1291.

4 Chodzko-Zajko WJ, Proctor DN, Fiatarone Singh MA, Minson CT, Nigg CR, Salem GJ, Skinner JS: American College of Sports Medicine position stand. Exercise and physical activity for older adults. Med Sci Sports Exerc 2009;41:1510-1530.

5 Hamer M, Chida Y: Physical activity and risk of neurodegenerative disease: a systematic review of prospective evidence. Psychol Med 2009;39:3-11.

6 Llamas-Velasco S, Contador I, Villarejo-Galende A, Lora-Pablos D, Bermejo-Pareja F: Physical activity as protective factor against dementia: a prospective population-based study (NEDICES). J Int Neuropsychol Soc 2015;21:861-867.

7 Forbes D, Forbes SC, Blake CM, Thiessen EJ, Forbes S: Exercise programs for people with dementia. Cochrane Database Syst Rev 2015;4:CD006489.

8 Ohman H, Savikko N, Strandberg TE, Pitkala KH: Effect of physical exercise on cognitive performance in older adults with mild cognitive impairment or dementia: a systematic review. Dement Geriatr Cogn Disord 2014; 38:347-365.

9 Schlosser Covell GE, Hoffman-Snyder CR, Wellik KE, Woodruff BK, Geda YE, Caselli RJ, Demaerschalk BM, Wingerchuk DM: Physical activity level and future risk of mild cognitive impairment or dementia: a critically appraised topic. Neurologist 2015;19:89-91.

10 Grande G, Vanacore N, Maggiore L, Cucumo V, Ghiretti R, Galimberti D, Scarpini E, Mariani C, Clerici F: Physical activity reduces the risk of dementia in mild cognitive impairment subjects: a cohort study. J Alzheimers Dis 2014;39:833-839.

11 Groot C, Hooghiemstra AM, Raijmakers PG, van Berckel BN, Scheltens P, Scherder EJ, van der Flier WM, Ossenkoppele R: The effect of physical activity on cognitive function in patients with dementia: a meta-analysis of randomized control trials. Ageing Res Rev 2016;25:13-23.

12 Miller LA, Spitznagel MB, Busko S, Potter V, Juvancic-Heltzel J, Istenes N, Glickman E, Gunstad J: Structured exercise does not stabilize cognitive function in individuals with mild cognitive impairment residing in a structured living facility. Int J Neurosci 2011;121:218-223.

13 Doi T, Makizako H, Shimada H, Tsutsumimoto K, Hotta R, Nakakubo S, Park H, Suzuki T: Objectively measured physical activity, brain atrophy, and white matter lesions in older adults with mild cognitive impairment. Exp Gerontol 2015;62:1-6.

14 Makizako H, Liu-Ambrose T, Shimada H, Doi T, Park H, Tsutsumimoto K, Uemura K, Suzuki T: Moderateintensity physical activity, hippocampal volume, and memory in older adults with mild cognitive impairment. J Gerontol A Biol Sci Med Sci 2015;70:480-486.

15 Farina N, Tabet N, Rusted J: The relationship between habitual physical activity status and executive function in individuals with Alzheimer's disease: a longitudinal, cross-lagged panel analysis. Neuropsychol Dev Cogn B Aging Neuropsychol Cogn 2016;23:234-252.

16 Frederiksen KS, Verdelho A, Madureira S, Bazner H, O’Brien JT, Fazekas F, Scheltens P, Schmidt R, Wallin A, Wahlund LO, Erkinjunttii T, Poggesi A, Pantoni L, Inzitari D, Waldemar G: Physical activity in the elderly is associated with improved executive function and processing speed: the LADIS study. Int J Geriatr Psychiatry 2015;30:744-750.

17 Bourassa KJ, Memel M, Woolverton C, Sbarra DA: Social participation predicts cognitive functioning in aging adults over time: comparisons with physical health, depression, and physical activity. Aging Ment Health $2015 ; 1-14$.

18 Meguro K, Tanaka N, Nakatsuka M, Nakamura K, Satoh M: Vascular lesions in mixed dementia, vascular dementia, and Alzheimer disease with cerebrovascular disease: the Kurihara Project. J Neurol Sci 2012;322: 157-160.

19 Meguro K: A Clinical Approach of Dementia: Instructions for the CDR Worksheet (in Japanese). Tokyo, IgakuShoin, 2004

20 Morris JC: The Clinical Dementia Rating (CDR): current version and scoring rules. Neurology 1993;43:24122414.

21 Takada J, Meguro K, Sato Y, Chiba Y: Life concerns of elderly people living at home determined as by community general support center staff: implications for organizing a more effective integrated community care system. The Kurihara Project. Psychogeriatrics 2014;14:188-195.

22 Nakamura K, Kasai M, Ouchi Y, Nakatsuka M, Tanaka N, Kato Y, Nakai M, Meguro K: Apathy is more severe in vascular than amnestic mild cognitive impairment in a community: The Kurihara Project. Psychiatry Clin Neurosci 2013;67:517-525.

23 Baillon S, Dennis M, Lo N, Lindesay J: Screening for depression in Parkinson's disease: the performance of two screening questions. Age Ageing 2014;43:200-205. 
24 Ainsworth BE, Haskell WL, Herrmann SD, Meckes N, Bassett DR Jr, Tudor-Locke C, Greer JL, Vezina J, WhittGlover MC, Leon AS: 2011 Compendium of Physical Activities: a second update of codes and MET values. Med Sci Sports Exerc 2011;43:1575-1581.

25 Guidetti L, Placentino U, Baldari C: Reliability and criterion validity of the smartphone inclinometer application to quantify cervical spine mobility. Clin Spine Surg 2016, Epub ahead of print.

26 Japan Statistics Bureau: The 2011 survey on time use and leisure activities. Tokyo, Ministry of Internal Affairs and Communications of Japan, 2013. http://www.stat.go.jp/english/data/shakai/2011/h23kekka.html.

27 Haskell WL, Lee IM, Pate RR, Powell KE, Blair SN, Franklin BA, Macera CA, Heath GW, Thompson PD, Bauman A: Physical activity and public health: updated recommendation for adults from the American College of Sports Medicine and the American Heart Association. Med Sci Sports Exerc 2007;39:1423-1434.

28 Farina N, Tabet N, Rusted J: Habitual physical activity (HPA) as a factor in sustained executive function in Alzheimer-type dementia: a cohort study. Arch Gerontol Geriatr 2014;59:91-97.

29 van Uffelen JG, Chinapaw MJ, van Mechelen W, Hopman-Rock M: Walking or vitamin B for cognition in older adults with mild cognitive impairment? A randomised controlled trial. Br J Sports Med 2008;42:344-351.

30 Schwenk M, Zieschang T, Oster P, Hauer K: Dual-task performances can be improved in patients with dementia: a randomized controlled trial. Neurology 2010;74:1961-1968.

31 Liu-Ambrose T, Eng JJ: Exercise training and recreational activities to promote executive functions in chronic stroke: a proof-of-concept study. J Stroke Cerebrovasc Dis 2015;24:130-137.

32 Dalton C, Sciadas R, Nantel J: Executive function is necessary for the regulation of the stepping activity when stepping in place in older adults. Aging Clin Exp Res 2015, Epub ahead of print.

33 Perrochon A, Kemoun G, Watelain E, Dugue B, Berthoz A: The 'Stroop Walking Task': an innovative dual-task for the early detection of executive function impairment. Neurophysiol Clin 2015;45:181-190.

34 Baker LD, Frank LL, Foster-Schubert K, Green PS, Wilkinson CW, McTiernan A, Plymate SR, Fishel MA, Watson GS, Cholerton BA, Duncan GE, Mehta PD, Craft S: Effects of aerobic exercise on mild cognitive impairment: a controlled trial. Arch Neurol 2010;67:71-79.

35 Dustman RE, Ruhling RO, Russell EM, Shearer DE, Bonekat HW, Shigeoka JW, Wood JS, Bradford DC: Aerobic exercise training and improved neuropsychological function of older individuals. Neurobiol Aging 1984;5: 35-42.

36 Perrig-Chiello P, Perrig WJ, Ehrsam R, Staehelin HB, Krings F: The effects of resistance training on well-being and memory in elderly volunteers. Age Ageing 1998;27:469-475.

37 van Uffelen JG, Chin APMJ, Hopman-Rock M, van Mechelen W: The effect of walking and vitamin B supplementation on quality of life in community-dwelling adults with mild cognitive impairment: a randomized, controlled trial. Qual Life Res 2007;16:1137-1146.

38 Hill RD, Storandt M, Malley M: The impact of long-term exercise training on psychological function in older adults. J Gerontol 1993;48:P12-P17.

39 Meguro K, Tanaka N, Kasai M, Nakamura K, Ishikawa H, Nakatsuka M, Satoh M, Ouchi Y: Prevalence of dementia and dementing diseases in the old-old population in Japan: The Kurihara Project. Implications for long-term care insurance data. Psychogeriatrics 2012;12:226-234.

40 Denkinger MD, Nikolaus T, Denkinger C, Lukas A: Physical activity for the prevention of cognitive decline: current evidence from observational and controlled studies. Z Gerontol Geriatr 2012;45:11-16.

41 Kishimoto H, Ohara T, Hata J, Ninomiya T, Yoshida D, Mukai N, Nagata M, Ikeda F, Fukuhara M, Kumagai S, Kanba S, Kitazono T, Kiyohara Y: The long-term association between physical activity and risk of dementia in the community: the Hisayama Study. Eur J Epidemiol 2016;31:267-274.

42 Laurin D, Verreault R, Lindsay J, MacPherson K, Rockwood K: Physical activity and risk of cognitive impairment and dementia in elderly persons. Arch Neurol 2001;58:498-504.

43 Best JR, Davis JC, Liu-Ambrose T: Longitudinal analysis of physical performance, functional status, physical activity, and mood in relation to executive function in older adults who fall. J Am Geriatr Soc 2015;63:11121120.

44 Godefroy O, Bakchine S, Verny M, Delabrousse-Mayoux JP, Roussel M, Pere JJ; REFLEX study group: Characteristics of Alzheimer's disease patients with severe executive disorders. J Alzheimers Dis 2016;51:815-825.

45 Foster ER, Cunnane KB, Edwards DF, Morrison MT, Ewald GA, Geltman EM, Zazulia AR: Executive dysfunction and depressive symptoms associated with reduced participation of people with severe congestive heart failure. Am J Occup Ther 2011;65:306-313.

46 Daly M, McMinn D, Allan JL: A bidirectional relationship between physical activity and executive function in older adults. Front Hum Neurosci 2014;8:1044.

47 Boyle CP, Raji CA, Erickson KI, Lopez OL, Becker JT, Gach HM, Longstreth WT Jr, Teverovskiy L, Kuller LH, Carmichael OT, Thompson PM: Physical activity, body mass index, and brain atrophy in Alzheimer's disease. Neurobiol Aging 2015;36(suppl 1):S194-S202. 